\title{
Lições de identidade presentes em livros didáticos de séries iniciais*
}

\section{Identity lessons in early grades of elementary school textbooks}

\author{
Letícia Fonseca Richthofen de Freitas**
}

\begin{abstract}
RESUMO
É indubitável o papel que os livros didáticos ocupam nas salas de aula de todo o país, mesmo com o crescente avanço das novas tecnologias. Mais do que um recurso largamente utilizado por professoras e professores em suas práticas educativas, os livros didáticos são artefatos culturais que produzem saberes. Neles estão presentes e circulam as mais diversas pedagogias culturais, as quais ensinam lições que vão muito além dos conteúdos curriculares, convidando alunos e alunas a ocuparem determinadas posições de sujeito. A partir de tais considerações, o presente trabalho se dedica à análise das pedagogias culturais presentes e atuantes nos livros didáticos, mais especificamente, a análise está centrada na assim chamada pedagogia do gauchismo, termo cunhado para designar as diversas formas como as pessoas aprendem a ser gaúchas, em diversas instâncias sociais e culturais. $\mathrm{O}$ estudo compara de que maneira a pedagogia do gauchismo está presente em livros de História das Séries Iniciais do Ensino Fundamental, no período que vai de 1960 a 2005, suas recorrências e rupturas. As análises apontam para uma predominância de uma determinada forma de se entender a identidade gaúcha, relacionando-a, sobretudo, à figura emblemática e mítica do gaúcho. Esta representação predominante constitui uma forte pedagogia cultural, produtora de saberes, a qual ensina uma maneira de ser gaúcho, convidando alunos e alunas a ocuparem posições de sujeito e

* Este estudo integra o meu projeto de pesquisa de Pós-Doutorado Júnior, realizado junto ao grupo de pesquisa do NECCSO (Núcleo de Estudos Sobre Currículo, Cultura e Sociedade) da UFRGS (Universidade Federal do Rio Grande do Sul), com apoio do CNPq, processo 155539/2006-0, sob a supervisão da Prof ${ }^{\mathrm{a}}$. Dr ${ }^{\mathrm{a}}$. Rosa Maria Hessel Silveira.

** Licenciada em Letras pela Pontifícia Universidade Católica do Rio Grande do Sul, Mestre e Doutora em Educação pelo Programa de Pós-Graduação em Educação da Universidade Federal do Rio Grande do Sul. Atualmente é bolsista do CNPq e pesquisadora do Núcleo de Estudos Sobre Currículo, Cultura e Sociedade/ NECCSO (<www.ufrgs.br/neccso $>$ ) da UFRGS, onde desenvolve a segunda fase de seu projeto de pesquisa de Pós-Doutorado Júnior.
\end{abstract}


a se constituírem identitariamente a partir de tal pedagogia.

Palavras-chave: Pedagogias culturais; Pedagogia do gauchismo; livro didático.

\begin{abstract}
While men technologies spread throughout the country, the role that textbooks play in classrooms is unquestionable. Further than a tool widely used by teachers (men and women) in their educational practices, textbooks are cultural artefacts producing knowledge. Multiple cultural pedagogies are present and circulate in them, teaching lessons that go much beyond the curricular content, encouraging students (men or women) to be in particular subject positions. From these observations, the present paper is devoted to analysing the current, active and cultural pedagogies in textbooks, most specifically the so-called gauchismo pedagogy, a term that was coined to designate how people learn to be a "Gaucho" (someone from Rio Grande do Sul state) in different social and cultural situations. The study has investigated how the gauchismo pedagogy is present in early grades of elementary school history textbooks, from 1960 to 2005, its recurrences and ruptures. Data points to a prevailing way to understand the Gaucho identity, particularly relating it to the symbolic and mythic Gaucho. This prevailing representation is a strong cultural pedagogy, producing knowledge, which teaches how to be a Gaucho, encouraging students to be in subject positions and identifying with this pedagogy.
\end{abstract}

Keywords: Cultural pedagogies; Gauchismo Pedagogy; textbooks.

Embora o vertiginoso crescimento das novas tecnologias possibilite, a cada dia, mudanças significativas no espaço escolar e nas práticas educativas, é evidente, também, o papel privilegiado que os livros didáticos ainda desempenham nos processos de ensino e de aprendizagem. Mesmo com todas as discussões em torno da inclusão digital, em muitas de nossas escolas públicas o livro didático continua sendo um dos únicos recursos disponíveis. Além de ser um recurso didático de extrema importância, o livro didático é um artefato cultural que produz os mais variados saberes, ensinando lições que transcendem os conteúdos curriculares.

A partir de tais considerações, o presente trabalho se dedica à análise das pedagogias culturais presentes e atuantes nos livros didáticos, mais especificamente, a análise está centrada na assim chamada pedagogia do gauchismo, 
termo cunhado para designar as diversas formas como as pessoas aprendem a ser gaúchas, em diversas instâncias sociais e culturais, dentre elas a Escola. O estudo compara de que maneira a pedagogia do gauchismo está presente em livros de História das Séries Iniciais do Ensino Fundamental, no período que vai de 1960 a 2005, suas recorrências e rupturas. As análises efetuadas apontam para uma predominância de uma determinada forma de se entender a identidade gaúcha, relacionando-a, sobretudo, à figura emblemática e mítica do gaúcho figura masculina, ligada à vida rural e à região da Campanha sul-rio-grandense, ao cavalo, e, mais recentemente, ao gauchismo e ao tradicionalismo.

\section{A gênese do gauchismo/tradicionalismo}

Antes de passar à análise da inserção da figura do gaúcho nos livros didáticos, será feita uma breve referência ao período histórico que se segue à criação do primeiro Centro de Tradições Gaúchas (CTG), no estado do Rio Grande do Sul, em 1948. A criação do primeiro CTG teve como uma de suas consequências a valorização da história do Rio Grande do Sul, em uma de suas versões, qual seja, a que narra de forma grandiosa algumas das lutas ocorridas no território sul-rio-grandense e descreve a região, seus aspectos físicos, geográficos e humanos como se fossem transcendentes e não contingentes. Ela, a terra gaúcha, o "pampa", aparece narrada desde sempre como um prenúncio, uma promessa que "naturalmente" viria a ser cumprida. Nesse sentido, vale lembrar que a história regional "não leva em conta o fato de que uma época ou um espaço não preexistem aos enunciados que os exprimem, nem às visibilidades que os preenchem" (ALBUQUERQUE JR., 1999, p. 29). Central ao discurso historiográfico regionalista sul-rio-grandense é o estabelecimento da figura mítica do gaúcho, este também narrado como uma promessa gloriosa, herói que teria atravessado altivamente guerras e adversidades, tipo humano rude - mas gentil - que assim se constituiu somente por uma necessidade imposta pelo meio, conforme argumenta um dos representantes do tradicionalismo gaúcho:

Embora rude, o gaúcho era extremamente gentil para com as mulheres e destemido na defesa da honra dos indefesos. As constantes carneações, o churrasco meio cru, sua familiarização à lida campeira constante, o contato com o sangue, tornava-o sempre preparado para a guerra. [...] $\mathrm{Na}$ descendência telúrica encontramos as razões para um ser tão rude, forte e corajoso, ligado profundamente à terra,que chamou, carinhosamente, de Torrão (LAMBERTY, 2000, p. 16). 
Da citação acima podemos perceber algumas das características básicas presentes no chamado "mito do gaúcho": a oscilação entre a rudeza e a gentileza, a coragem e a bravura, a prontidão para a peleia, o amor à terra, ao pago, tão presentes hoje em dia no discurso tradicionalista, sendo todas estas características supostamente adquiridas pela influência do meio e transmitidas aos gaúchos.

Segundo Oliven (1993), há vários momentos nesse culto à figura do gaúcho, e ele deve ser entendido como parte de várias condições históricas que tornaram possível tanto esta construção imagético-discursiva do gaúcho, quanto o seu aspecto encomiástico.

Assim, cabe aqui ressaltar o fato de que, em 1947, alguns jovens do Colégio Estadual Júlio de Castilhos, em Porto Alegre, criaram o Departamento de Tradições Gaúchas do Grêmio Estudantil, organizando a primeira Ronda Gaúcha, de 7 a 20 de setembro daquele ano. Também naquele ano foi instituída a Chama Crioula:

tomando uma centelha do Fogo Simbólico da pira da Pátria antes de sua extinção às 24 horas do dia 7 de setembro, transportaram-na até o saguão do Colégio Júlio de Castilhos onde acenderam a "Chama Crioula" num candieiro de galpão (OLIVEN, 1990, p. 11).

Na sequência dessas iniciativas, foi fundado, em 24 de abril de 1948, o 35 CTG - Centro de Tradições Gaúchas -, numa referência ao ano de deflagração da Revolução Farroupilha, em 1835.

Conforme a versão mais aceita pelos historiadores, a Revolução Farroupilha teve início no dia 20 de setembro de 1835, liderada pelo coronel Bento Gonçalves, com o apoio dos estancieiros. A criação de gado era, desde o final do século XVIII, a base da economia do Rio Grande do Sul e o charque, o seu principal produto, era consumido em todo o país. Os estancieiros gaúchos, porém, sofriam a concorrência dos países platinos - Argentina e Uruguai -, os quais, por produzirem o charque com mão-de-obra livre, o vendiam por preços mais baixos. $\mathrm{O}$ governo brasileiro hesitava em adotar medidas protecionistas a favor dos criadores brasileiros. Em 1834, um novo aumento de impostos para a província gaúcha propiciou o início da rebelião. Em 1835 o presidente da província, nomeado pelo governo central, foi deposto, e os rebeldes proclamaram a República Rio-Grandense. A revolução se prolongou por 10 anos, sendo que os rebeldes foram derrotados e um tratado de paz foi assinado. A Revolução Farroupilha é comemorada até hoje no Rio Grande do Sul, sendo o dia 20 de setembro considerado o Dia do Gaúcho. As comemorações da Revolução Far- 
roupilha mobilizam todo o estado do Rio Grande do Sul, desde Escolas até o governo estadual.

No início, seus fundadores pretendiam que o centro fosse uma agremiação de, no máximo, trinta e cinco participantes, mas depois foi decidido que ela estaria aberta para todos os que dela quisessem participar. O grupo passou então a se reunir aos sábados, para tomar chimarrão e imitar os hábitos do interior, como as charlas dos peões nos galpões das estâncias.

À criação do primeiro Centro de Tradições Gaúchas, seguiu-se a "criação" de várias tradições, a fim de incrementar os hábitos e os costumes da região da Campanha e das estâncias, as quais os fundadores do movimento julgavam ser as "autênticas" tradições gaúchas. A esse respeito escreve Oliven (1993, p. 15-16) que

Embora não quisessem constituir uma entidade que refletisse sobre a tradição, mas um grupo que procurasse revivê-la, era necessário recriar o que imaginavam ser os costumes do campo. Assim, a estrutura interna do 35 CTG não utilizou a nomenclatura que normalmente existe em associações, mas adotou os nomes usados na administração de um estabelecimento pastoril, já que os jovens queriam evocar o ambiente de uma estância. No lugar de presidente, vice-presidente, secretário, tesoureiro, diretor, etc. empregaramse os títulos de patrão, capataz, sota-capataz, agregados, posteiros, etc. No lugar de Conselhos Deliberativos ou Consultivos, foi colocado o Conselho de Vaqueanos, e em vez de departamentos foram criadas invernadas. De forma semelhante todas as atividades culturais, cívicas ou campeiras, receberam nomes que tivessem origem nos usos e costumes das estâncias gaúchas, tais como rondas, rodeios, tropeadas, etc.

Depois da criação do 35 CTG houve, paulatinamente, uma proliferação de Centros de Tradições Gaúchas por todo o estado do Rio Grande do Sul, em outros estados e no exterior. Esse movimento de criação de vários CTGs marca o processo de consolidação de uma tradição inventada, a qual se apresenta, até os dias atuais, como sendo "a" tradição gaúcha. As práticas e o discurso tradicionalistas buscam justamente estabelecer uma continuidade histórica, tentando fixar certos rituais e fazer com que os gaúchos se constituam como tal, valendo-se, para isso, das tradições, muitas delas "inventadas", e do discurso que privilegia o passado e a memória que seria comum a todos. Albuquerque Jr. (1999, p. 79) observa que o discurso tradicionalista 
toma a história como o lugar da produção da memória, como discurso da reminiscência e do reconhecimento. Ele faz dela um meio de os sujeitos do presente se reconhecerem nos fatos do passado, de reconhecerem uma região já presente no passado, precisando apenas ser anunciada. Ele faz da história o processo de afirmação de uma identidade, da continuidade e da tradição, e toma o lugar de sujeitos reveladores desta verdade eterna, mas encoberta.

A preocupação do Movimento Tradicionalista Gaúcho - MTG, fundado em 1966, com a formação de novos gauchinhos e prendinhas se faz clara já no primeiro Congresso Tradicionalista, realizado em Santa Maria no ano de 1954, ocasião em que Barbosa Lessa (2000) defendeu a tese "O Sentido e o Valor do Tradicionalismo", na qual aparecem as duas grandes questões do Tradicionalismo. Assim, ao lado da assistência a ser dada ao homem do campo, a grande questão é a atenção a ser dada às novas gerações a partir do ambiente escolar, pois, segundo o seu autor,

Deve, o Tradicionalismo, operar com intensidade no setor infantil ou educacional, para que o movimento tradicionalista não desapareça com a nossa geração. [...] Por isso não temo afirmar que o dia mais glorioso para o movimento tradicionalista será aquele em que a classe de Professores Primários do Rio Grande do Sul - consciente do sentido profundo desse gesto, e não por simples atitude de simpatia - oferecer seu decisivo apoio a esta campanha cultural.

Aliás, não se concebe que as Escolas Primárias continuem por mais tempo apartadas do movimento tradicionalista. Pois a maneira mais segura de garantir à criança o seu ajustamento à sociedade é precisamente fazer com que ela receba, de modo intensivo, aquela massa de hábitos, valores, associações e reações emocionais - o patrimônio tradicional, em suma imprescindíveis para que o indivíduo se integre eficientemente na cultura comum.

A partir das considerações feitas até aqui, pode-se afirmar que, depois de 1950, o aparecimento de temas ligados ao gauchismo e à figura do gaúcho se dá de maneira mais efetiva nos livros didáticos. No que se refere especificamente à pedagogia do gauchismo, sua inserção nos livros didáticos é bastante significativa, ensinando e produzindo os mais diversos saberes sobre a gauchidade. Apesar de o discurso do gauchismo estar presente durante toda a vida escolar de alunos e alunas, é nas primeiras séries do Ensino Fundamental que eles são 
privilegiados, uma vez que tais narrativas e representações estão presentes no material didático adotado, sobretudo nos livros.

\section{Os livros didáticos e a produção de saberes identitários}

Conforme já foi mencionado acima, apesar do crescente avanço das novas tecnologias, as quais têm alterado significativamente o cotidiano escolar, é inegável o importante papel desempenhado pelos livros didáticos nos processos de ensino e de aprendizagem. Como todos nós, professores e professoras, sabemos, mesmo com todas as discussões em torno da inclusão digital, em muitas de nossas escolas públicas o livro didático continua sendo um dos únicos recursos - e talvez o mais importante - disponíveis. De acordo com Bittencourt (2006, p. 71), o livro didático "continua sendo o material referencial de professores, pais e alunos que [...] consideram-no referencial básico para o estudo".

O livro didático é um artefato cultural que produz os mais variados saberes, "é por seu intermédio que são passados os conhecimentos e técnicas considerados fundamentais de uma sociedade em determinada época" (BITTENCOURT, 2006, p. 72). No caso da pedagogia do gauchismo, foi possível identificar a sua presença nos livros didáticos adotados no Rio Grande do Sul no período analisado, sendo esta uma pedagogia que produz saberes a respeito do gaúcho.

No que se refere às representações do gaúcho encontradas nos livros didáticos pesquisados, pode-se afirmar, em síntese, que há a recorrência daquela figura tradicional, masculina, associada à região da Campanha, ao cavalo, à indumentária típica - bota, bombacha, lenço, boleadeiras, esporas, chapéu, etc. - à vida rural, enfim, uma imagem bastante conhecida país afora. Será mostrada, a seguir, a título de exemplificação, a maneira como o gaúcho é descrito nos livros didáticos em diversas épocas. Os dois primeiros excertos foram extraídos de livros da década de 1960 (a grafia da época foi mantida):

O gaúcho é o tipo regional da campanha sul-rio-grandense.

Percorre as coxilhas onduladas, montado no pingo, seu companheiro inseparável.

Sua habitação natural é a estância. [...]

São muito característicos seus trajes: usa bombachas, lenço ao pescoço, a guaiaca, isto é, um cinturão largo no qual coloca a faca, o revólver e 
o dinheiro; botas de couro com esporas, que tilintam quando anda, e um chapéu de feltro de abas largas e barbicacho.

Quando sopra o minuano, envolve-se no seu poncho.

Sentado, à sombra de frondosos umbus e velhas figueiras, come o churrasco, carne mal passada, feita ao espeto.

À noite, os gaúchos reúnem-se no galpão, onde contam "causos" e cantam, enquanto a cuia passa de mão em mão (THOFEHRN; CUNHA, 1963, p. 22 e 23).

Na campanha rio-grandense é que vamos encontrar o gaúcho, tipo característico da região.

O gaúcho é, em geral, franco, sincero e hospitaleiro. Respeita a família e a palavra empenhada. É decidido, valente e leal na luta.

É hábil cavaleiro e excelente laçador. Seu alimento preferido é o churrasco e sua bebida predileta o chimarrão (BOPP; CABRAL, 1969, p. 47 e 48).

Na página seguinte o livro apresenta a seção "Como se veste o gaúcho", listando e explicando tudo aquilo que faz parte de sua indumentária - "chapéu, lenço, pala, camisa, guaiaca, tirador, esporas, relho, isqueiro, bombachas e botas" (BOPP; CABRAL, 1969, p. 49).

Quase quarenta anos depois, alunos e alunas, ao folhearem seu livro didático e estudarem a identidade gaúcha, encontram uma descrição bem próxima daquelas acima destacadas:

O gaúcho é o tipo característico da Campanha. [...]

O gaúcho, quando se veste a rigor, costuma usar as seguintes vestimentas: chapéu de abas largas, barbicacho, camisa de pano, lenço de pescoço, guaiaca, chiripá, botas com esporas, tirador, bombacha, poncho, pala.

Os hábitos do gaúcho são em geral ligados à vida no campo. Os mais conhecidos são:

- fazer do cavalo um companheiro - o gaúcho procura nunca se separar do cavalo. O cavalo é chamado pelo gaúcho de "pingo".

- ser hábil no uso do laço e ágil no uso de boleadeiras.

- apreciar um bom churrasco - geralmente uma carne malpassada, assada sobre brasas, com ou sem espeto. 
- saborear o chimarrão - bebida de mate cevado sem açúcar. É sempre servido a um visitante, num gesto de hospitalidade e cordialidade (KOTECK, 2000, p. 100-104).

Para finalizar os exemplos, abaixo há a transcrição de um último excerto de um livro editado em 2001, no qual também fica explícita a maneira recorrente como o gaúcho é descrito:

No ambiente da Campanha houve modificações através do tempo.

Nas estâncias modernas há o caminhão, a caminhonete, luz elétrica. Há mais conforto e rapidez no trabalho. O gaúcho de hoje ouve rádio, vê televisão. Porém, com todas essas mudanças, o gaúcho conserva os mesmos hábitos e o mesmo espírito: continua sendo tão bom cavaleiro quanto seus antepassados, é laçador, domador. [...] Toma sempre o chimarrão e come churrasco. Continua olhando os campos com o mesmo encantamento, tem amor pela terra e pelos animais.

Desse tipo gaúcho herdamos a simplicidade, a coragem, e generosidade, a sinceridade (SCHNEIDER, 2001, p. 80).

Cabe ressaltar que foram extraídos os trechos considerados mais significativos do amplo espectro de livros pesquisados, justamente por julgar importante sublinhar o fato de que, apesar de o intervalo de tempo existente ser grande - década de 1960 até 2005- entre os livros pesquisados, a representação do gaúcho, no que tange a suas características, tanto físicas quanto psicológicas, não sofreu alterações significativas. Sendo assim, conforme foi sinalizado no início, os saberes produzidos pelos livros didáticos a respeito do gaúcho giram em torno da figura masculina - sendo esta representação de gênero fortemente marcada, uma vez que a figura da mulher, a prenda, é totalmente secundária -, havendo uma predominância da sua ligação com a vida rural, na região da Campanha. Além disso, também é recorrente a descrição da indumentária gaúcha, a qual, provavelmente, deva ser familiar para crianças que participam de um ambiente onde se cultivam as tradições, principalmente nas cidades do interior, onde é mais comum convivermos com pessoas pilchadas ${ }^{1}-$ homens parcial ou totalmente pilchados, pois as mulheres não costumam usar vestido

1. Pilchada é uma pessoa vestida com a indumentária tradicionalista gaúcha: para os homens, tal vestimenta inclui bombacha, chapéu, lenço vermelho, boleadeiras, botas; já as mulheres devem trajar o vestido de prenda. 
de prenda no cotidiano, até pelo incômodo de tal indumentária - fazendo esta vestimenta parte do dia-a-dia dessas crianças. Para outros gauchinhos e gauchinhas, entretanto, este tipo de gaúcho pode ser tomado como uma figura mais folclórica, presente em determinados espaços e situações, como festas juninas e comemorações da Revolução Farroupilha, por exemplo. De toda forma, esta é a maneira predominante de o tipo gaúcho se nos tornar visível - pilchado maneira esta que privilegia a instituição da representação de uma figura que passa a ser a imagem "natural", "normal", presente nos livros didáticos e em outros meios. Segundo Costa (1998, p. 42) "quando alguém ou algo é descrito, explicado, em uma narrativa ou discurso, temos a linguagem produzindo uma 'realidade', instituindo algo com existente de tal ou qual forma". Institui-se, assim, uma maneira de se vestir gaúcha, e junto com, atrelada a ela, uma maneira de se constituir gaúcho.

Merecem destaque também os termos empregados para se fazer referência ao gaúcho e ao seu universo: "costumes", "hábitos", "estância", "cavalo", "origem", "peões", "tradicional", "cultivar", "antigo", dentre outros. São termos que concorrem para a fixação da imagem de gaúcho aqui analisada, um gaúcho que tem a sua origem no campo, peão de estância, que possui hábitos e costumes antigos, os quais são cultivados até hoje e que nos foram legados. No que tange às características psicológicas do gaúcho, são usados os adjetivos "franco", "sincero", "hospitaleiro", "decidido", "valente", "leal", "cordial", "simples", "corajoso", "generoso", qualidades essas que reforçam uma identidade marcada por um campo semântico positivo. Obviamente não se está querendo afirmar que gaúchos e gaúchas não possuam tais qualidades; o que é importante sublinhar é que essas características não se restringem aos gaúchos, elas também se aplicam a todas as outras identidades, sejam elas nacionais, regionais, de gênero, de classe, etc.

Apesar de, como já foi dito anteriormente, a representação do gaúcho nos livros didáticos não ter sofrido alterações significativas no intervalo de tempo pesquisado, a maneira como essas representações - essa imagem de gaúcho - aparecem nos livros se modificou. Em relação a tais modificações, cabe destacar, em primeiro lugar, as mudanças ocorridas no mercado editorial brasileiro, sobretudo no mercado de livros didáticos.

A reforma de ensino da década de 1970, que tem como suporte a Lei de Diretrizes e Bases - LDB 5692/71, aumentou o número de professores, de alunos e de escolas, "favorecendo o incremento da produção industrial de livros, os quais passavam a contar com um segmento de demanda bastante seguro" (BORDINI, 1998, p. 38). Nesse sentido, Gatti Júnior (2005) afirma que, na década de 1990, o suporte comercial das grandes editoras brasileiras era o livro didático - situação que perdura até os dias de hoje. Em 1970 ocorreu 
o "boom" editorial dos livros didáticos, sendo que, nos anos de 1980, a rede escolar foi fartamente abastecida, pelo governo, de livros não apenas didáticos e paradidáticos, mas também de literatura infanto-juvenil, havendo um enorme contraste com a produção quase artesanal presente na realidade da indústria editorial brasileira da década de 1960 .

É só a partir de 1970, então, que os livros vão ganhando um número maior de ilustrações - que passam a ser coloridas - e começa a ocorrer a segmentação por disciplinas, uma vez que, até então, havia somente um ou dois livros que abordavam as várias áreas do conhecimento. Devido a este panorama, as representações do gaúcho presentes nos livros mais antigos que foram analisados - de 1960 a 1970 geralmente estão inseridas em um único livro, editado em preto-e-branco, que abordava praticamente todas as áreas curriculares - os livros pesquisados podem ser agrupados da seguinte maneira em relação à divisão das disciplinas: Linguagem e Estudos Sociais; Linguagem e Estudos Sociais e Naturais; Linguagem, Matemática, Estudos Sociais, Moral e Cívica.

Nos livros desse período, a figura do gaúcho se destaca tanto na parte que se refere a Estudos Sociais quanto à Linguagem - nesta última aparecem textos de autores consagrados na Literatura Brasileira e sul-rio-grandense, como Simões Lopes Neto, Augusto Meyer, Érico Veríssimo, Manoelito de Ornelas, Darcy Azambuja, dentre outros.

Em relação às ilustrações, como já foi afirmado anteriormente, há uma profusão delas nos livros editados a partir de 1970, sendo que os da década de 1990 em diante apresentaram uma quantidade grande de gravuras e de ilustrações, mapas, fotos, ou seja, todos os recursos técnicos disponíveis são utilizados no sentido de produzir um livro didático mais atraente para alunos e alunas que, cada vez mais, possuem outros recursos plenos de imagens que os seduzem - como Internet, vídeo-game e a própria televisão. É importante sublinhar, todavia, a presença de ilustrações que retratam a figura do gaúcho e os sistemas simbólicos a ela associados - paisagem rural, chimarrão, churrasco, detalhes da indumentária, cavalo, etc. - em todos os livros analisados. Ocorre que, no período que abrange 1960 a 1970, geralmente aparecem desenhos e figuras em preto-e-branco ou com pouquíssimas cores; já a partir de 1970, como mencionado, o número de ilustrações aumenta significativamente, bem como os recursos gráficos utilizados na produção dos livros didáticos.

Ainda no que tange à abordagem dada à figura do gaúcho nos livros didáticos, um outro fator importante a ser ressaltado é a associação paulatina que vai haver entre a figura do gaúcho e sua identidade com o gauchismo/tradicionalismo - o termo gauchismo pode ser considerado mais amplo, indicando tudo aquilo que se refere ao gaúcho, e não somente aquilo que é ligado ao tradicionalismo. Tal associação pode ser explicada pela influência que os Centros 
de Tradições Gaúchas (CTGs) e posteriormente o Movimento Tradicionalista Gaúcho (MTG) adquirem a partir de 1948, data da criação do primeiro CTG, conforme já abordado na seção anterior.

Sendo assim, a influência do gauchismo, sobretudo a partir da fundação e expansão dos CTGs e da sua vertente tradicionalista, faz-se cada vez mais presente nos livros didáticos, havendo, inclusive, a referência ao movimento em alguns dos livros mais recentes, conforme transcrito nos excertos abaixo:

O povo gaúcho valoriza muito suas tradições. Em todo o estado encontramos os CTG - Centro de Tradição Gaúcha - onde se cultivam os hábitos gauchescos como o churrasco, o carreteiro, o chimarrão, as danças folclóricas, as músicas e lendas (JARDIM, 1995, p. 163).

O movimento tradicionalista gaúcho, que mantém vivos os costumes antigos das estâncias e recorda a cultura da Campanha, teve impulso com a criação dos CTGs. O primeiro foi criado em 1948 e, hoje, existem muitos CTG espalhados por todo Rio Grande do Sul e também por vários outros estados do país (MENEGOTTO; OLIVEIRA, 1999, p. 147).

Com base nessas considerações, pode-se afirmar a importância de se estudar as pedagogias culturais presentes nos livros didáticos, uma vez que elas ensinam lições e produzem saberes que estão muito além dos conteúdos curriculares. No caso da pedagogia do gauchismo, a representação predominante analisada neste estudo produz saberes identitários, os quais ensinam uma maneira de ser gaúcho, convidando alunos e alunas a ocuparem posições de sujeito e a se constituírem a partir de tal pedagogia. 


\section{REFERÊNCIAS}

ALBUQUERQUE JR., D. M de. A invenção do Nordeste e outras artes. São Paulo: Cortez, 1999.

BITTENCOURT, C. M. F. Livros didáticos entre textos e imagens. In: (Org.). O saber histórico na sala de aula. São Paulo: Contexto, 2006. p. 69-90.

BOPP, S. S.; CABRAL, E. F. Linguagem e Estudos Sociais. Porto Alegre: Edições Tabajara, 1969.

BORDINI, M. da G. A Literatura Infantil nos anos 80. In: SERRA, E. D. (Org.). 30 Anos de Literatura para crianças e jovens: algumas leituras. Campinas-SP: Mercado de Letras: Associação de Leitura do Brasil, 1998. p. 33-45.

COSTA, M. V. Currículo e política cultural. In: do contemporâneo. Rio de Janeiro: DP\&A, 1998. p. 37-68. .(Org.). O currículo nos limiares

GATTI JR., D. Estado e editoras privadas no Brasil: o papel e o perfil dos editores de livros didáticos (1970-1990). Caderno Cedes, Campinas, v. 25, n. 67, set./dez. 2005. Disponível em: $<$ http://www.cedes.unicamp.br>. Acesso em: 26/08/2006.

KOTECK, L. M. Conhecendo o Rio Grande do Sul. São Paulo: Ática, 2000.

LAMBERTY, S. F. ABC do tradicionalismo gaúcho. Porto Alegre: Martins Livreiro, 2000.

LESSA, Luiz Carlos Barbosa. O sentido e o valor do tradicionalismo. Disponível em: $<$ http://www.mtg.org.br>. Acesso em: 20/03/2008.

MENEGOTTO, R.; OLIVEIRA, G. M. Rio Grande do Sul. História e Geografia. São Paulo: Quinteto Editoral, 1999.

OLIVEN, R. G. A dupla desterritorialização da cultura gaúcha. In: FONSECA, C. (Org.). Fronteiras da cultura. Horizontes e territórios da antropologia na América Latina. Porto Alegre: Editora da Universidade/UFRGS, 1993. p. 24-40.

. "O maior movimento de cultura popular do mundo ocidental": o tradicionalismo gaúcho. Cadernos de Antropologia, n. 1, Porto Alegre: UFRGS/IFCH, 1990.

SCHNEIDER, R. P. História do Rio Grande do Sul. São Paulo: FTD, 2001.

THOFEHRN, C. C.; CUNHA, N. Estrada Iluminada. Canto da Minha Terra. São Paulo: Editora do Brasil, 1963. 